\title{
Artigos
}

\section{A Marcha das Vadias e seu feminismo: \\ Práticas, experiências e conflitos de uma geração de jovens feministas ${ }^{1}$}

Janaína Vargas*

Jurema Brites**

\section{Resumo}

0 artigo apresenta uma reflexão acerca das relações geracionais de jovens engajadas na luta feminista. A partir de uma pesquisa etnográfica realizada junto ao Coletivo Marcha das Vadias de Santa Maria, no Rio Grande do Sul, desenvolvemos uma discussão a respeito da articulação dos novos movimentos sociais em sua interface com as dinâmicas de uma prática feminista marcada pela atuação em espaços da internet. As disputas entre diferentes práticas políticas dessas jovens são descritas como parte da configuração de um feminismo contemporâneo, marcado por disputas simbólicas que articulam novas formas de ação política, manifestadas por fragmentação, fluidez, efemeridade e primazia das pautas imateriais.

\section{Palavras-chave}

Marcha das Vadias. Feminismo. Juventude.

\section{Abstract}

The article presents a reflection on the generational relations of young women engaged in the feminist struggle. Based on an ethnographic research carried out with the Coletivo Marcha das Vadias (SlutWalk Coletive) of Santa Maria, Brazil, we developed a discussion about the

\footnotetext{
${ }^{1}$ Estudo realizado por Janaína Vargas sob orientação de Jurema Brites, entre 2014 a 2016, para obtenção do título de Mestra em Ciências Sociais pela Universidade Federal de Santa Maria (UFSM).

* Janaína Vargas é Mestre em Ciências Sociais (UFSM, 2016) atua como professora das disciplinas de História e Artes nas instituições Anglo Americano e CAESP na cidade de Foz do Iguaçu, Paraná. E-mail: naina.vargas@gmail.com.

** Jurema Brites é Doutora em Antropologia pela Universidade Federal do Rio Grande do Sul (2000); e professora assistente de Antropologia no Departamento de Ciências Sociais da Universidade Federal Santa Maria (UFSM). E-mail: juremagbrites@gmail.com.
} 
articulation of the new social movements in their interface with the dynamics of a feminist practice marked by the performance in spaces of the internet. The article points out the disputes between different political practices of these young women in the contemporary feminism, marked by symbolic disputes that articulate new forms of political action, manifested by fragmentation, fluidity, ephemerality and primacy of immaterial agenda.

\section{Keywords}

Slutwalk. Feminism. Youth.

\section{Marcha das Vadias e Feminino}

Entre 2015 e 2016, Janaína Vargas desenvolveu uma etnografia de um grupo localizado de mulheres participantes da Marcha das Vadias² e que faziam parte do Coletivo da Marcha das Vadias de Santa Maria (CMVSM). Esse coletivo não se limitava à realização do ato de rua da Marcha, mas também proporcionava discussões e debates feministas, de caráter formativo, através da realização de oficinas, feiras e participação de eventos na cidade. Entretanto, passados alguns meses, o grupo não resistiu às dissensões internas e rompeu. Neste artigo, intentamos analisar as articulações da Marcha das Vadias na cidade de Santa Maria (RS), desenvolvendo uma discussão sobre movimentos sociais contemporâneos, feminismo e juventude.

Um ano depois de iniciado o trabalho de campo com as mulheres do CMVSM, soubemos que o grupo havia decidido terminar suas atividades. Observamos que as disputas e discordâncias entre as interlocutoras eram elementos analíticos ideais para o entendimento de tal remate. Esse percurso deflagrou na observação da pluralidade do movimento feminista contemporâneo e seus conflitos internos, que pressupomos estarem ligados

\footnotetext{
${ }^{2}$ Em janeiro de 2011, em decorrência de vários casos de abusos sexuais contra mulheres na Universidade de Toronto, no Canadá, o policial Michael Sanguinetti realizou uma palestra sobre prevenção a esse crime. Na fala, o policial disse às mulheres que "evitassem se vestir como vadias (sluts, em inglês), para não serem vítimas". O descontentamento de várias mulheres foi imediato, pois, para elas, a afirmação retratou uma visão distorcida a respeito da condição feminina. Assim, em abril de 2011, mulheres de Toronto realizaram uma manifestação de rua, denominada SlutWalk, traduzida por Marcha das Vadias no Brasil (MANBRINI, 2011).
} 
a uma questão geracional e de formação de identidades, lógica inscrita nos modos atuais de se fazer política: fragmentação, fluidez, efemeridade e primazia das pautas imateriais.

As principais pautas e reivindicações do CMVSM eram de caráter essencialmente feminista, como a luta pela liberação sexual e autonomia dos corpos. Como outros movimentos contemporâneos, a Marcha teve uma potência mobilizadora muito contundente na internet. Cazarré (2016, s/p) cita algumas campanhas que, mesmo não deslocando pessoas para as ruas, ganharam rápida adesão, numa convecção de opiniões tão imediatas que são descritas pela noção de epidemia. São "hashtags como: \#PrimeiroAssédio, \#MeuAmigoSecreto e \#AgoraÉqueSãoElas, que viralizaram ${ }^{3}$ nas redes e contribuíram para um debate em torno de feminismo, preconceito, igualdade de direitos e salários, entre outros". As redes sociais digitais (como o Facebook) passaram a ser um espaço virtual no qual as mulheres denunciam violências, tornando-se importante instrumento para expandir informações, realizar ações, arquitetar estratégias e trocar opiniões, várias destas em prol de transformações sociais.

Aliado a esse feminismo virtual, aparece também um elemento importante: as novas gerações 4 . Oliveira (2014, s/p) observa que "muitas das novas militantes são mulheres jovens, educadas na era digital, que passaram a juventude inteira ouvindo que homens e mulheres já tinham direitos iguais". Assim, esse "novo feminismo" é multifacetado, jovem e impiedoso com as promessas não realizadas. Gonçalves e Pinto (2011) reforçam que há uma dimensão do feminismo assinalada como "geracional", instigada no interior do movimento pela intervenção de jovens que reivindicam voz e presença.

Vinculado ao aspecto geracional, o movimento feminista adquiriu também diferentes formas de protesto. Ao escrever sobre essas mudanças, Moschkovich (2014) questiona: "existe, então, um novo feminismo?" O cyberativismo feminista ganhou muita força e popularizou nos últimos 15

\footnotetext{
${ }^{3}$ Viralizar é uma expressão para postagens que têm uma enorme visibilidade na internet.

${ }^{4}$ De acordo com a Fundação Perseu Abramo, "de 2001 a 2010 aumentou de 21\% para 31\% o contingente de brasileiras que se consideram feminista. [...] Quarenta por cento das jovens entre 15 e 17 anos, a faixa etária mais jovem da amostra, se consideram feministas, seguidas das jovens de 25 a 34 anos, com $37 \%$ de identificação, e, em último lugar, as mulheres maiores de 60 anos com 23\%" (GOMES; SORJ, 2014, p. 434).
} 
anos. Mesmo assim, tais estratégias não foram específicas do movimento e continuaram reproduzindo em nova roupagem algumas ações tradicionais da militância política (MOSCHKOVICH, 2014, p.1).

As demandas no movimento feminista atual tomam novas formas de militância e de articulação, no entanto, reproduzem reivindicações tradicionais de militância, até mesmo porque muitas pautas de luta não foram superadas ${ }^{5}$.

\section{Rede de Significados, de Movimentos e de Conflitos}

O CMVSM, assim como o ato de rua organizado por ele (Marcha das Vadias), foi construído diante de acordos e ajustes de diferentes feminismos na cidade de Santa Maria (RS). No interior do coletivo, moças com distintas experiências e pensamentos ligaram-se em um espaço participativo mais amplo, através de vínculos de solidariedade e propósitos políticos em comum. Dentro desse espaço de práticas, enfrentaram desafios de articulação, entre os quais estavam conflitos que as levaram a acabar com o grupo. Mesmo que o ato de rua da marcha mostrasse aparente abertura às múltiplas formas de resistências, as diferenças de vertentes feministas e o desacordo sobre a participação dos homens foram muito disputados.

Para Melucci, os movimentos sociais são redes de movimentos que unem núcleos e grupos de indivíduos a um espaço participativo mais amplo. Assim, "o que é empiricamente chamado de 'movimento social', na verdade, é um sistema de ação que liga orientações e significados plurais" (MELUCCI, 1989a, p.56). A ação coletiva contemporânea passou a ser estruturada em diferentes "áreas de interesse", como redes compostas por multiplicidade de grupos dispersos, fragmentados e submersos na vida cotidiana.

\footnotetext{
${ }^{5}$ A história do feminismo é didaticamente dividida em ondas. A primeira, entre meados do século XIX e início do XX, focava a igualdade nos direitos de contratos, de propriedade e na oposição de casamentos arranjados. O movimento sufragista foi o marco desse período. A segunda onda (1960 a 1990) se caracterizou pela luta por igualdade e pelo fim da discriminação em relação às mulheres, salientando o direito ao prazer sexual, ao aborto, a confrontação aos modelos patriarcais de família e a invisibilidade das mulheres perante as leis jurídicas. A terceira onda destacou o "feminismo da diferença", desconstruindo a universalização da mulher ao admitir a diversidade social e política mesmo no interior das categorias sexuais e de gênero.
} 
O movimento social é "a luta contra um adversário para a apropriação e o controle de recursos valorizados por ambos" (MELUCCI, 2001, p. 35) e, nesse contexto, sempre existirá um rival (inimigo). Na estrutura de um movimento social e dessa relação oposicionista é que se constituem as orientações para um processo de conformação de uma concepção de luta e uma identidade coletiva. Nesse viés, um ato conflituoso está relacionado à conduta de atores discordantes em um mesmo sistema social. Pensando a partir do movimento observado em Santa Maria, os homens e/ ou o sistema patriarcal são os inimigos centrais. Nesse caso, há um inimigo duplo a ser enfrentado: a discussão sobre o homem, como sujeito masculino concreto, e o sistema patriarcal, em termos de valores, visão de mundo e suas práticas.

O Coletivo, embora composto por jovens feministas, apresentava diversificadas expectativas sobre o que o "feminismo inclui ou exclui" (GOMES; SORJ, 2014, p. 437). Elas compartilhavam experiências, espaços de sociabilidade, informações (na internet principalmente) e preferências musicais, literárias, artísticas, entre outras. Essas trocas podem ser pensadas como redes de significados (MELUCCI, 1989b), que permitem uma agregação múltipla, um envolvimento pessoal e uma solidariedade afetiva. A solidariedade seria "a capacidade dos atores de partilharem uma identidade coletiva" (MELUCCI, 1989a, p. 57) e, nessa partilha, o conflito é inevitável, pois faz parte da relação entre os indivíduos, estando presente tanto nos espaços internos do movimento quanto nos espaços externos das práticas militantes.

As ações das mulheres do coletivo perpassaram por práticas organizativas, que foram pensadas e desenvolvidas por um grupo de moças, brancas, universitárias, em sua maioria, com capitais intelectuais e sociais semelhantes (BOURDIEU, 1996), buscando um espaço de construção de pautas e práticas militantes. Essas redes de construção foram desenvolvidas diante de debates e acordos, com o objetivo de especificar os procedimentos de determinadas ações reivindicatórias.

Além disso, conforme Tarrow (1994), a ação coletiva possui poder para provocar os oponentes e estimular a solidariedade. A intensidade e a permanência da ação coletiva dependem da mobilização dos indivíduos e, no cenário das redes sociais digitais, articulam diferentes práticas para a gerência de suas ações. Uma das questões que necessita ser compreendida para refletirmos o desempenho e as estruturações de um movimento social é a pluralidade de pontos de vista. Compreendemos, diante disso, que as ações coletivas têm base em relações de significação determinadas 
por processos de identificação em constante exercício de negociação para a construção partilhada de uma coesão reflexiva de sujeitos que apontam projetos comuns.

\section{O Patriarcado e o Deslocamento do "Inimigo"}

Durante o trabalho de campo, diversas vezes a palavra patriarcado esteve aliada a um discurso combativo. Assim, analisar o conceito de patriarcado, através das singularidades em que as interlocutoras o significavam e como se portavam diante do seu reconhecimento, passou a ser estratégia essencial de compreensão de suas percepções. Sem tentar reconstituir historicamente seus desdobramentos, elencamos questões que, nas vozes das jovens estudadas, são importantes na construção de suas práticas e identidades feministas. O uso corrente do termo para exemplificar, combater ou explanar as desigualdades, injustiças e violações sofridas pelas mulheres era prática social que essas moças destacavam na sua ação política. Combater esse sistema de opressão era a ordem do dia do movimento.

No decorrer da observação, surgiu o questionamento: por que esse tema acabava criando uma atmosfera de discordância? No caderno de campo de Vargas (2016), encontramos a seguinte anotação: "Muito tensa a reunião de hoje. Saí pensando: se o problema era o patriarcado, de que maneira elas pretendiam derrotá-lo?". Para elas, a resposta seria simples: "desconstruindo machismos e não nos calando a este sistema opressor". Refletindo sobre essa questão, a etnógrafa admite um tanto constrangida que considerava ingênuo e frágil o pensamento das interlocutoras em relação às concepções e propostas de destruição do patriarcado.

As jovens não costumavam debater, via de regra, de maneira crítica e contextualizada, as questões histórico-teóricas do patriarcado, já que o desaprovavam enquanto uma realidade objetiva-persistente, algo dado e explicativo das subalternidades femininas. Mesmo com muitas participantes oriundas de cursos superiores da área das humanidades, nos quais o estudo sobre a construção do conceito de patriarcado provavelmente está presente em leituras sobre gênero, família e feminismo, não é a perspectiva acadêmica que anima as militantes. Nas palavras das pesquisadas, o patriarcado era o elemento constante e totalizador da explicação das desigualdades e subalternidades femininas. Por conseguinte, tornava-se categoria de acusação das situações e sujeitos opressores. O que queremos ressaltar aqui é o pouco apreço entre elas pela discussão acadêmica. O debate é pautado por uma 
realidade que é sentida como injusta para a totalidade das mulheres, e a causa é interpretada como decorrência do patriarcado também generalizado.

As diferenças também estavam ligadas diretamente às distintas correntes feministas com que cada uma delas "simpatizava". Uma parte das moças do coletivo reconhecia-se (e eram reconhecidas) como simpatizantes ou adeptas do feminismo radical. Para elas, o patriarcado deveria ser combatido pela "raiz". Assim, todo e qualquer espaço feminino em que um homem se fizesse presente deveria ser combatido, pois ele sempre assumiria a posição de opressor e, na maioria das vezes, protagonista. Porém, outras participantes não concordavam.

Certa tarde, uma moça segredou que se considerava uma feminista moderada. Para ela, seria importante não uma proposição de combate, mas de inserção feminina. As mulheres deveriam tomar os postos e nichos masculinos neste sistema impossível de destruir. Já as moças que se denominavam adeptas do feminismo interseccional pensavam que a marcha e o Coletivo deveriam ser abertos a todos e todas que fossem apoiar a luta. Essas disputas, que no início da pesquisa pareciam secundárias, tomaram proporções muito agressivas, apimentadas pelo debate correlato nos grupos feministas na internet.

Naquele contexto, surgiu outra indagação: por que as tensões que emergiam nas discussões entre pesquisadas sobre o que se entendia enquanto patriarcado parecia, por fim, não ser o ponto central das diferenças entre elas? Para parte do movimento, o conceito de patriarcados e substancializava e era desviado para outro foco de combate, cujo verdadeiro inimigo a ser combatido não era mais o sistema patriarcal, mas sim seu beneficiário, o homem. Nesse contexto, o inimigo principal também eclodia em outras questões importantes, como nas diferentes correntes feministas, nas quais cada uma delas se via representada.

\section{A Pluralidade das Correntes Feministas e o Lugar dos Homens}

Quando se propõe falar do movimento feminista, cabe observar a pluralidade de pensamentos, consequência das diferentes classes, gerações, vivências e opressões a que diversas mulheres são submetidas. Nesse contexto, pensar o feminismo que se constrói entre as novas gerações e suas contradições é fundamental. Conduzimos essa análise ao perceber que a escolha do inimigo (patriarcado ou homem) que as investigadas propunham combater estava diretamente vinculada às diferentes correntes 
feministas. Durante a observação participante, a maioria das jovens ligadas ao CMVSM se identificava como feministas interseccionais ${ }^{6}$, mas ao mesmo tempo simpatizava com alguns princípios do feminismo radical.

O feminismo radical originou-se na década de 1960. As radfem, autodenominação de feministas radicais, partem da ideia etimológica da palavra radical, que significa "pertencer à raiz" ou "algo que vai à raiz", tendo um propósito revolucionário. O feminismo radical se coloca como "por e para as mulheres", centrando suas teorias e ações nas experiências e interesses "delas", tanto em termos de produção discursiva quanto de público-alvo. As radfem partem da lógica de que todas as mulheres são parte de um grupo oprimido, tendo estas que lutar não pelos outros, mas sim por elas mesmas, sem a tutela de homens, ou seja, propõe a volta à categoria mulher como a principal articuladora do feminismo (posição que os estudos de gênero relativizaram desde os anos 1980).

Um dos objetivos centrais consistia em socializar e conscientizar as mulheres em relação às opressões a que estão submetidas, almejando construir estratégias de libertação das mulheres. As radfems ficaram conhecidas, dentre outros motivos, por não aceitarem mulheres transexuais em espaços feministas (SARMENTO, 2015). Porém, cabe lembrar que, no caso específico desta pesquisa, as mulheres simpatizantes do radfem não se posicionavam contra a participação de transexuais nos espaços de atividades do CMVSM, o que mostra particularidades locais do movimento. A interseccionalidade as inspirava a compreender a opressão feminina como algo universal e fruto do patriarcado. $\mathrm{O}$ feminismo radical apontava para o norte da ação: protagonismo e poder às mulheres. Entretanto, não adotavam a perspectiva sexual como demarcação das desigualdades entre homens e mulheres, pois tomam a perspectiva construtiva de gênero e sexualidade.

Além das correntes de feminismo interseccional e radical, havia duas mulheres que se consideravam feministas socialistas. Elas disseram fazer parte da Marcha Mundial das Mulheres (MMM)7, movimento que

\footnotetext{
${ }^{6}$ As moças que se intitulavam interseccionais se apoiavam na perspectiva de Crenshaw (2002), que, tomando a situação das mulheres negras nos Estados Unidos, articula outras esferas de opressão, sobretudo classe e raça, as quais geram opressões articuladas.

${ }^{7}$ A Marcha Mundial das Mulheres originou-se em 2000 como uma mobilização reunindo mulheres do mundo todo em uma campanha contra a pobreza e a violência.O movimento defende a visão de que as mulheres são sujeitos ativos na luta pela transformação de suas vidas e que ela está vinculada à necessidade de superar o sistema capitalista patriarcal, racista, homofóbico e destruidor do meio ambiente. Disponível em: https:/ / marchamulheres. wordpress.com/mmm/. Acesso em: 12 nov. 2015.
} 
defende o feminismo marxista, também chamado de feminismo socialista. Em um dos lenços confeccionados para a Marcha, pintaram a frase: "sem feminismo não há socialismo". Essas moças eram engajadas, em termos formais, no movimento político. Faziam parte de tendências organizadas dentro dos partidos e não vêm possibilidade na libertação real das mulheres no sistema capitalista.

Entretanto, a interseccionalidade não é fácil de ser realizada. Certa ocasião, numa atividade do CMVSM com as Marias Bonitas ${ }^{8}$, discutiu-se o sentido da palavra "mulher". As respostas das Marias Bonitas foram: "mãe", "esposa" e "batalhadora". Em um segundo momento, a interlocutora perguntou sobre as palavras: "vadia" e "luta". As respostas imediatas foram: "galinhas", "vagabundas", "piranha", "puta".

A conversa envolveu uma reflexão sobre os usos e o poder dado à palavra "vadia". Para as integrantes do CMVSM, os homens utilizam a palavra "vadia" para justificar diferentes tipos de agressão masculina. E vadia "para oprimir as sexualidades, pois torna a mulher simples objeto de satisfação sexual masculina" (diário de 26/11/2014). Em meio a tais colocações, os intuitos básicos, para que o movimento saísse em protesto às ruas, foram explicados.

O objetivo dessa atividade era a troca de experiências entre os grupos. Entretanto, o que se verificou foram as moças do coletivo conduzindo as perguntas e reflexões e as Marias Bonitas realizando os depoimentos. Pouco se ouviu sobre as vidas das participantes do CMVSM. No diário de campo, foi anotado: "mulher era bicho batalhador, porque, além de ter que fazer boia para os maridos, tinha que cuidar dos filhos e trabalhar pra ter dinheiro no fim do mês" (26/11/2014). Embora dissonantes, tais depoimentos não geraram considerações sobre as diversidades de experiências de mulheres, mas sim a constatação de que tais mulheres da periferia ainda não conheciam o ideário de liberdade feminista.

Nessa atividade, ficou explícita a dificuldade do movimento de compreender que desconstrução de papéis sociais, como a maternidade, perpassa por elementos complexos e singulares a cada grupo social. Esse quadro de disputas foi crucial para a derrocada do CMVSM. Celina, interlocutora da pesquisa, comentou:

\footnotetext{
${ }^{8}$ Coletivo de mulheres de um bairro periférico da cidade. Esse realiza trabalhos buscando autonomia financeira e pessoal, como artesanato e costura.
} 
Era um espaço de disputa. No início, era um espaço de construção, em torno destas várias concepções. Mas no final, acabou em espaço de disputa, entre qual que deveria ser, por isso que gerou este término. Eu vejo como positivo o término da marcha, pois permaneceu a ideia de que a marcha não acabou, o que terminou, na verdade, foi o coletivo (CELINA, 2015).

O fim do coletivo representou o fim da marcha na cidade. No caso santamariense, as jovens tinham a perspectiva interseccional enquanto proposta unificadora, mas cada um dos três elementos (raça, classe e gênero) tensionava no sentido de inviabilizar a zona de intersecção: classe e gênero sobrepondo-se à raça. Surgiram críticas das mulheres negras às propostas do Coletivo. Uma delas falou: "em um coletivo onde a maioria das mulheres são brancas e privilegiadas, praticar um feminismo interseccional é algo bem utópico, já que as ações são voltadas e pensadas para esse tipo de mulher". Apesar das tensões "delas entre elas", a briga que culminou na derrocada do coletivo foi o papel dos homens.

Kamyla e Ane relataram que um dos principais motivos que acarretou o término do CMVSM foi a grande divergência interna referente à participação de homens nas atividades, assim como o papel deles no movimento. De um lado, em menor número, estavam aquelas que aprovavam a participação de homens, creditando que eles, ao apoiarem o movimento, podiam fortalecê-lo. De outro, aquelas que não aceitavam esta posição, acreditando que o coletivo, assim como o movimento feminista, era feito por e para as mulheres e que, se aprovada a presença masculina, correriam o risco de serem por eles silenciadas.

Cabe lembrar que este embate não é uma discussão somente das jovens pesquisadas, pois ele está presente nos últimos tempos em várias discussões de caráter feminista. Sobre essa questão, Lara e Leão (2015) afirmam que os homens, não sofrendo o machismo diretamente, não poderiam protagonizar o movimento feminista, podendo apenas apoiar e ouvir as mulheres. Em uma reunião do coletivo em que se discutia a construção da Batucada das Vadias ${ }^{9}$, umas das moças presentes ofereceu ajuda de um amigo, já que ele possuía instrumentos musicais. Esse ato gerou desacordo, pois, para algumas meninas, a Batucada era para ser dirigida e composta somente por

\footnotetext{
${ }^{9}$ Atividade para ensaiar as músicas para o ato de rua da Marcha das Vadias.
} 
mulheres. "É importante ver aquelas várias mulheres, batucando, gritando e proferindo suas vozes. Os zomis [homens] entrariam e tirariam essa visibilidade feminina", coloca uma das jovens. Outras moças acreditavam que os homens poderiam ser feministas. Elas partiam da afirmação de que eles, ao reivindicarem com as mulheres, estariam desconstruindo machismos.

Diferentemente da lógica das radfem, Tiburi (2015) acredita que, para alguém ser feminista, não precisa necessariamente ser mulher. Para ela, o feminismo

não pode excluir os homens alegando a categoria da 'natureza', usada pelos homens para dominar as mulheres. [...] O movimento feminista construiu-se como luta das mulheres e revela-se hoje, como a ético-política capaz de incluir na teoria e na prática todxs. Coisa que a dominação masculina jamais desejou. (TIBURI, 2015, p.1).

Cabe também ressaltar a importância que a internet teve nos embates travados pelas jovens pesquisadas, como um espaço de trocas de experiências e opiniões. As jovens do CMVSM gerenciavam um grupo aberto no Facebook ${ }^{10}$, palco de discussões calorosas referentes às divergências abordadas. Ao falar do fim do coletivo, Júlia comenta:

“[...] De repente, descobri, pelo grupo que eu estava no Facebook, onde algumas gurias falavam: "ah, eu vou me afastar do coletivo" ou, "vou sair do coletivo". Eu acho que um dos pontos-chave foi quando teve toda uma treta no grupo da marcha no Facebook. Os caras começaram a desautorizar as gurias, um monte de besteiras. Tinham duas gurias da marcha que eram administradoras deste grupo, e elas baniram o cara. [...] Lembro que eu tava em uma reunião e as gurias falaram que tinham combinado que se um cara viesse se meter com alguma guria, a gente ia banir imediatamente. O que aconteceu foi que, no fim, não nos sentimos apoiadas por essa decisão, mesmo ela sendo tomada em conjunto. Então, pra mim, aquela quebra foi muito forte. Isso foi muito desgastante,

\footnotetext{
${ }^{10}$ Disponível em: https://www.facebook.com/groups/301495893268668/. Acesso em 27 de maio de 2016. A página ainda existe, mas com moderadoras não mais do CMVSM. O grupo aberto caracteriza-se por deixar qualquer pessoa, sem autorização de mediadores, entrar no espaço, publicar, comentar e responder postagens.
} 
pois quando tu bane um cara e vem um monte de gurias defende, tendo ele sido agressivo com outras meninas, desestimula a gente. Uma das coisas desestimulante, pra mim, enquanto feminista, é quando uma menina vai defender o agressor e não fica do lado das meninas (JÚLIA, 2015)".

Depois dessa discussão que tomou corpo em dezenas de comentários na postagem, a atitude de querer banir o rapaz abriu uma brecha para que alguns membros do grupo (homens e, até mesmo, mulheres) passassem a se referir às moças que queriam bani-lo como feminazis. Tal termo é utilizado por várias pessoas, principalmente na internet, para fazer alusão às mulheres que argumentam um "feminismo extremista". Contrária ao uso do termo, Semírames (2010) demonstra que a expressão feminazi é uma ignorância a serviço do conservadorismo: "Feministas foram perseguidas pelos nazistas [...] mulheres deveriam obrigatoriamente ser mães, portanto estudos superiores e creches foram limitados, e aborto e métodos contraceptivos foram proibidos [...]." (SEMÍRAMES, 2010, p.1).

Feminazi trata-se de um termo de acusação, em referência estrita a uma postura autoritária de banir os homens do grupo e do debate público. É importante ressaltar que algumas militantes se apropriavam do termo feminazi, (re)significando-o uma forma de contrarresposta irônica. Observamos que algumas moças, geralmente as mais novas, colocavam em seus perfis nas redes sociais descrições como: "esquerdo pata feminazi", "lesbo-feminazi" e "sapata feminazi". Essas discussões geraram tensões e burburinhos entre as moças. Uma delas segredou que a falta de comunicação, de sinceridade e de franqueza entre elas foi também crucial para o fim das atividades do coletivo. Aos poucos, as atividades propostas por elas começaram a se esvaziar. E foi assim que, em uma reunião realizada no início de 2015, elas resolveram, sem muita conversa, pôr fim ao CMVSM.

\section{Juventude Feminista}

Além dos conflitos por formas de luta que envolvem conceitos e correntes feministas, as disputas internas foram também observadas nas manifestações da internet. Nesta última sessão pretendemos estender as interpretações dos espaços de conflito a outras possibilidades analíticas que inserem tais disputas também num processo geracional de construção identitárias de mulheres jovens. 
Muitas das moças ligadas ao Coletivo têm atuação cotidiana na internet, acompanhando blogs feministas e também participando de grupos de discussão no Facebook. Nesses grupos, divulgam críticas à cultura machista, compartilham produtos feministas, eventos e artigos. Em alguns deles, expressam apoios em situações críticas, como abusos físicos e psicológicos, brigas com a família, amigo/as, namorados/as; decisões e discussões sobre corpo, estética, identidade sexual, entre outros. Esse convívio, entretanto, está longe de ser harmônico, podendo ser, ao mesmo tempo, tenso, impiedoso e disruptivo.

Em geral, um post começa com apelo à intimidade e solidariedade entre as "manas". Em pouquíssimo tempo as respostas chegam e não é raro que haja discordância de posições. A discussão nem sempre é um debate, mas é comum as críticas serem árduas e rudes, dificultando o trabalho das mediadoras para que a pluralidade seja mantida. Nesses debates, as moças demonstram uma performance muito contundente, em que a discussão muitas vezes (ou quase sempre) escorrega para posições inflexíveis, nas quais a particularidade das experiências de alguém pode ser ofendida. Se uma mulher expressa uma opinião sobre uma injustiça sofrida, sempre haverá alguém ou algum grupo que não se sente representado e a contesta veementemente. Um dos argumentos para tais refutações advém da noção de protagonismo - uma perspectiva de autoridade do lugar da fala, que autoriza apenas a própria pessoa a expressar as situações vividas ou pensadas pela sua própria voz.

Entre nossas hipóteses interpretativas para tal dinâmica nas contendas, incluímos experiências geracionais e características da contemporaneidade, em que a individualidade se sobrepõe ao coletivo, a alteridade perde espaço para o particular e a internet se coloca como formatador do espaço e da experiência da fala. Sem nos atermos a uma noção cronológica de juventude, encontramos essas jovens (16 e 28 anos) vivendo um momento de construção de suas vidas em termos acadêmicos, de sexualidade, de estéticas e de valores políticos. Muitas declaram dúvidas quanto à escolha dos cursos e profissões, experimentam variadas formas de sexualidade e identidade de gênero, seu estilo de vestir ou seus corpos não se conformam aos modelos padrão e a reflexão política feminista é sua marca de expressão intelectual. Na composição desses perfis, o feminismo aparece como uma chave que desvela experiências passadas e promessas de uma sociedade mais justa ainda não articulada.

Em contraste à célebre elucidação de Simone de Beauvoir, “Não se nasce 
mulher, torna-se mulher". Essas moças afirmaram, muitas vezes durante a pesquisa: "Eu sempre fui feminista e não sabia". Assim, nos seus relatos, o feminismo vem desnudar situações de violência concreta ou simbólicas reconhecidas não apenas nas suas próprias vivências, mas também das mulheres a sua volta. O feminismo, nessas situações, se torna uma chave organizadora e explicativa das experiências negativas e uma promessa de reconstrução possível. Coerentemente com isso, seus pronunciamentos políticos, em geral, assemelham-se a de adolescentes aguerridas, num processo de ajuste de contas denunciador das promessas de vida digna, justa e de respeito que afinal não aparecem nem nas famílias nem nas relações mais amplas da sociedade ${ }^{11}$. Suas performances políticas expressam-se bastante emocionalizadas e dramáticas, sem acordos e concessões.

Quando abordamos geracionalidade, tentamos descrever comportamentos observados nas manifestações políticas atuais, em que o radicalismo de posição, a individualidade da condição de cada situação ou sujeito e o espaço da internet compõem possibilidades expressivas com vantagens e desvantagens para os movimentos sociais em termos de construções de pautas políticas. Alguns autores substancialistas pensaram a juventude como uma etapa de transição a partir de elementos biológicos intransponíveis (HALL, 1921). Outros, porém, preferem associar os fatos psicológicos individuais a contextos socioculturais (ERICKSON, 1989; TARTUCE, 2007). Para essa corrente, a noção de juventude é própria das sociedades pós-revolução industrial, no qual a centralização do trabalho acaba por conformar uma tríade geracional. A juventude tomada como tempo de formação e preparação, a vida adulta como ideal a ser alcançado pelo trabalho estável e autonomia e a velhice como etapa do descanso.

Com as mutações da sociedade pós-modernas, tais fronteiras entre as gerações, no entanto, tornaram-se borradas. Stecanela (2010) afirma que nas sociedades onde não há pleno emprego, nem estabilidade no mercado do trabalho, as mudanças de sensibilidades e valores alteraram as noções de ruptura e autonomia em relação à geração anterior. Hoje, os filhos permanecem mais tempo na casa dos pais, a família substitui o

\footnotetext{
${ }^{11}$ Reichert (2013, p. 293) apresenta a noção da adolescência como um momento revisionista, no qual o "adolescente reedita crises e dificuldades do desenvolvimento anterior, sendo impulsionado a fazer uma revisão geral do passado, antes de ingressar na vida adulta. É um verdadeiro pente fino, que detecta e reflete as pendências, na tentativa de integrar esses conflitos, enquanto a identidade se estrutura".
} 
mercado/estado na inserção e preparação dos jovens para a vida adulta, e a sexualidade não precisa mais de uma nova moradia para se estabelecer. A juventude passa ser vista em mais de sentido: como geração em potencial, reserva latente, mas também como ideal a ser perseguido pelo mundo adulto. Uma postergação do processo de juvenilização, em que "os jovens buscam encontrar na vida dos mais velhos alguma perspectiva de futuro, mas encontram um espelho de si mesmo" (KHEL apud STECANELA, 2010, p. 73). Tais características juvenis do grupo estudado podem ser observadas nas formas comunicacionais e nas construções políticas contemporâneas em geral. Estas são muito bem realçadas nos debates das redes sociais digitais, em que parece haver uma segmentação exagerada dos pontos de vista individuais em detrimento da capacidade de diálogo e construção de pautas políticas comuns.

A internet pode atuar aqui como um lugar propiciador do desenvolvimento da individualidade contemporânea, o exercício de ser fiel a si de tal modo a nunca se conformar com algo que possa ser englobado por um conjunto. Por outro lado, pode também ser um facilitador da manifestação e do treino de expressão da individualidade, na medida em que a presença distante que conecta cada um com todos protege o interlocutor de uma resposta imediata e sensível de desaprovação. A desvantagem talvez articule um desestímulo pela empatia e uma adesão à diferença. A noção de particularidade essencial do indivíduo, movido por uma ideia de igualdade e liberdade, ideal que tanto aqueceu os movimentos políticos e o feminista, é, na opinião de Dumont (1997), a promessa inatingível do mundo moderno ocidental, pois a igualdade absoluta é irreal, e a liberdade de cada um é agonística.

\section{Considerações Finais}

Ao observar o CMVSM, percebemos que as reivindicações principais perpassavam sempre a busca por autonomia e liberdade das mulheres. $\mathrm{O}$ corpo era a pauta central de militância. Elas defendiam a legalização do aborto, o direito de ir e vir sem medo de sofrerem abusos e agressões em função da vestimenta e o direito de escolha das parcerias sexuais. No caso santa-mariense, as jovens tinham a perspectiva interseccional enquanto proposta unificadora do coletivo, mas isso não se efetivava na prática. $\mathrm{O}$ debate sobre a participação dos homens nas atividades propostas, assim como a questão sobre eles se intitularem feministas, tomou grandes 
proporções e foi central para a dissolução do grupo.

A internet, ambiente que disseminou o movimento da Marcha das Vadias pelo mundo, acabou sendo também palco das discussões e divergências causadoras do colapso do CMVSM. Foi nela que a maioria das moças iniciou sua formação política, através de blogs e páginas feministas, fazendo com que o debate fosse marcado pelas lógicas da conversação da internet. Nesse contexto é que foi forjado o termo feminazi enquanto crítica às posturas radicais de algumas militantes, assim como sua apropriação irônica. Esse caráter ambivalente também foi observado em relação às liberdades individuais, ponto central das reivindicações do movimento. Por um lado, esse individualismo se configurou enquanto seu fundamento, por outro, a particularização dos corpos e percepções acabou por resultar em entraves para a ação coletiva.

Por fim, lembramos que são jovens em processo de construção de si que tomam o caminho do feminismo como umas das estradas de vida e neste trajeto não conseguiram construir um processo que transpassasse as demandas e identificações em prol de um programa amplo de reivindicações. No entanto, esta não é marca apenas de determinada fase geracional, senão uma lógica inscrita nos novos modos de fazer política: fragmentação, fluidez, efemeridade e primazia das pautas imateriais que fazem levar adiante as novas reconfigurações da ação política.

\section{Referências}

BOURDIEU, Pierre. (1996). Razões Práticas: sobre a Teoria da Ação. Papirus Editora.

DUMONT, Louis.

(1997). Homo-hierarchicus: o sistema de cartas e suas implicações. São Paulo: EDUSP.

CAZARRÉ, Marieta.

(2015). A “quarta onda do feminismo" nasce em 2015. Revista Brasileiros.

ERICKSON, Erik.

(1988). 0 ciclo de vida completo. Porto Alegre: Artemed.

CRENSHAW, Kimberlé.

(2002). Documento para o encontro de especialistas em aspectos da discriminação racial relativos ao gênero. Estudos Feministas: ano 10. Disponivel em: http://www.scielo.br/ pdf/ref/v10n1/11636.pdf. Acesso em: 20 jun. 2015.

GOMES, Carla; SORJ, Bila.

(2014). Corpo, geração e identidade: a Marcha das Vadias no Brasil. Revista Sociedade $e$ Estado, v. 29, n. 2, maio/ago, p. 233- 447.

HALL, Stanley.

(1921). Aspects of child life and education. New York: P. Appleton. 
LARA, Bruna de; LEÃO, Bruna.

(2015). Homens podem ser feministas? Não me kahlo. Disponível em: http://www.naomekahlo. com/\#!Homens-podem-serfeministas/ c1a1n/55935c3e0cf2c7ea473b64fd. Acesso em: 4 jan. 2016.

MELUCCI, Alberto.

(1989a). Um objetivo para os movimentos sociais? Lua Nova. São Paulo, n. 17, p.50-66.

(1989b). Nomads of the present. Social movements and individual needs in contemporary society. Filadelfia: Temple University Press.

(2001).A invenção do presente. Rio de Janeiro: Vozes.

MOSCHLOVICH, Marília.

(2014). Existe, então, um "novo" feminismo? Outras Palavras: comunicação compartilhada e pós-capitalismo. Disponível em: http:// outraspalavras.net/posts/existe-entao-umnovo-feminismo/. Acesso em: 28 dez. 2015.

OLIVEIRA, Graziele.

(2014). A nova luta das mulheres. Época. Disponivel em: http://epoca.globo.com/ ideias/noticiFa/2014/02/bnova-lutabdasmulhereshtml. Acesso em: 17 dez. 2015.

REICHERT, Evania.

(1991). Infância - a idade sagrada. Anos sensiveis que nascem as virtudes e os vícios humanos. Porto Alegre: Vale do Ser.

SARMENT0, Raysa.

(2015). Feminismo, reconhecimento e mulheres trans*: expressões online de tensões. Pensamento Plural. Pelotas, p. 129-150.
SEMÍRAMES, Cynthia.

(2010). Feminazi: ignorância a serviço do conservadorismo. Blog Cynthia Semírames.

STECANELA, Nilda.

(2010). Jovens e Cotidiano: trânsitos pelas culturas juvenis e pelas escolas da vida. Caxias do Sul: Educs.

TARROW, Sydney.

(1994). El poderen movimiento: los movimientos sociales, La acción colectiva y La política. Madrid: Alianza Editorial.

TARTUCE, Gisela.

(2007). Tensões $e$ intensões na transição escola trabalho: um estudo das vivencias e percepções dos jovens sobre os processos de qualificação profissional e re(inserção) no mercado de trabalho na cidade de São Paulo. Tese de Doutorado, Universidade de São Paulo.

\section{TIBURI, Márcia.}

(2015). Democracia hard: homens, feminismo e machismo ao contrário. Revista Cult. Disponível em: http://revistacult.uol. com.br/home/2015/06/democracia-hardhomens-feminismo-emachismoao-contrario. Acesso em: 6 jan. 2016.

\section{Recebido em}

novembro de 2017

\section{Aprovado em}

março de 2018 